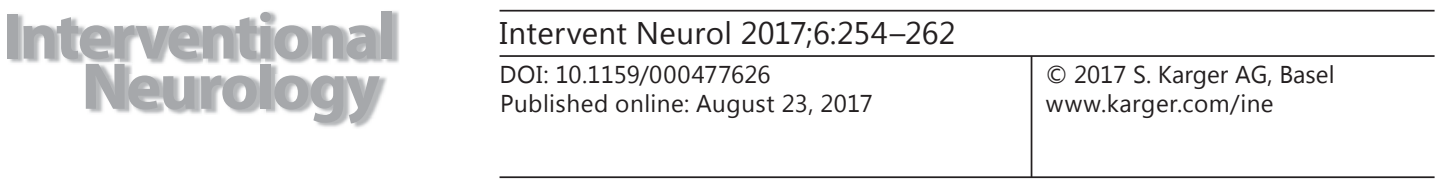

\title{
Multimodal Therapy for Non-Superacute Vertebral Basilar Artery Occlusion
}

\author{
Xiongjun $\mathrm{He}^{\mathrm{a}}$ Liang Zhang ${ }^{\mathrm{a}} \quad$ Juan Yang $^{\mathrm{a}}$ Hui Zheng ${ }^{\mathrm{b}}$ Kaifeng $\mathrm{Li}^{\mathrm{a}}$ \\ Yajie Liu $^{\mathrm{a}}$ \\ a Department of Neurology, Zhujiang Hospital, Southern Medical University Guangzhou, \\ and ${ }^{\mathrm{b}}$ Department of Neurology, Nanfang Hospital, Southern Medical University \\ Guangzhou, Guangzhou, China
}

\section{Keywords}

Vertebrobasilar insufficiency - Acute stroke - Thrombectomy - Endovascular treatment .

Recanalization

\begin{abstract}
Objective: The aim of this study was to evaluate the feasibility and safety of multimodal therapy for patients with non-superacute vertebral basilar artery occlusion. Method: We performed a retrospective analysis of multimodal therapy for patients with vertebral basilar artery occlusion. All patients who were beyond the time window to receive intravenous thrombolysis and who had deterioration of symptoms after drug treatment received smallballoon dilatation of the occlusive artery to estimate vascular occlusion aetiology. Thrombectomy with a Solitaire $A B$ system was applied to the thrombus, and angioplasty with intracranial stents was used to treat stenosis. During the 3-month follow-up, National Institute of Health Stroke Scale (NIHSS) and modified Rankin scale (mRS) scores were recorded regularly. Results: We included 12 patients with a mean age of 60.4 (SD: 12.9) years. The average score on the NIHSS was 16.6 (SD: 11.6), and the average time from onset to admission was $95 \mathrm{~h}$ (SD: 121). The arteries were recanalized for all patients, but the degree of residual stenosis in the parent artery was $17.5 \%$ (SD: 20.1). During the follow-up period, one patient died of pulmonary haemorrhage and infection, and another patient died from haemorrhage related to high
\end{abstract}

Xiongjun He and Liang Zhang contributed equally to this work.

Dr. Yajie Liu

Department of Neurology, Zhujiang Hospital, Southern Medical University

Industrial Road 253, Haizhu District

Guangzhou 510282 (China)

E-Mail 2804219902 @qq.com 
perfusion. After 3 months of follow-up, the 10 surviving patients showed an average NIHSS score of 7.9 (SD: 8.7) and an average mRS score below 2 (1.3 \pm 1.4$)$. Conclusion: For patients with posterior circulation stroke due to basilar artery or vertebral artery occlusion who present to the hospital $6 \mathrm{~h}$ after symptom onset and who exhibit deterioration of symptoms after drug treatment, multimodal recanalization of the occluded artery may be a feasible and safe therapy.

(c) 2017 S. Karger AG, Basel

\section{Introduction}

The basilar artery supplies most of the brain stem, thalamus and occipital lobes and part of the cerebellum. Patients with acute basilar artery occlusion can present with symptoms that vary from coma to quadriplegia, abnormal movements of the eye and pupil, dysphagia or sudden death. Approximately $20 \%$ of ischaemic strokes are caused by basilar artery occlusion [1]. Basilar artery occlusion is an infrequent and catastrophic disease that accounts for $20 \%$ of ischaemic stroke cases [1]. The mortality rate of basilar artery occlusion is up to 85-95\% even with fibrinolytic and anticoagulant therapy if the artery is not recanalized $[1,2]$. Though the outcomes of malignant middle cerebral artery occlusion are poor, with a mortality rate of 41-79\%, basilar artery occlusion has a higher mortality rate [3,4]. In 2009, the largest basilar artery occlusion data registry from the Basilar Artery International Cooperation Study (BASICS) showed that the mortality rate of patients receiving conservative treatment could be up to $54 \%$, and only $3 \%$ of these patients had a good outcome. There was no significant increase in good outcomes after intra-arterial thrombolysis (IAT) and mechanical thrombectomy (MT) compared with conservative therapy [5]. Conversely, patients with a severe deficit (defined as quadriplegia, coma or locked-in syndrome) seemed to benefit from recanalization therapy, including intravenous thrombolysis (IVT), IAT and MT, with the absolute risk of death decreasing by 19 and $10 \%$. Due to the low recanalization rate of IVT, IAT combined with MT or multimodal vascular recanalization therapy (combination of IVT, IAT and MT) is recommended for acute posterior circulation stroke patients within the therapeutic time window, but there is no clear recommendation for those beyond the time window for thrombectomy.

\section{Methods}

Population and Methods

This study was approved by the institutional review board of Medicine. Written informed consent was obtained from each participant according to institutional guidelines. From August 2012 to April 2016, we collected clinical data from 12 patients with non-superacute posterior circulation stroke in the Department of Neurology at Zhujiang Hospital of Southern Medical University. All patients presented with symptoms of acute posterior circulation ischaemia and presented to the hospital within $10 \mathrm{~h}$ to 2 weeks of symptom onset (average 93.5 h). Each patient underwent brain stem infarction. Among these patients, 3 patients also had cerebellar hemisphere infarction, 1 patient also had large-area brain infarction in the left cerebellum and vermis, 4 patients also had occipital infarction, and 2 patients were transferred to the hospital due to deterioration of symptoms after IVT therapy with recombinant tissue plasminogen activator. All patients were male, and their ages ranged from 41 to 77 (average 60.4) years. In addition, 11 patients had high blood pressure, 3 patients had diabetes, 1 patient had coronary atherosclerotic cardiomyopathy, 4 patients had a history of smoking, and 6 patients had hyperlipidaemia (Tables 1,2).

All patients were diagnosed with intracranial double vertebral artery occlusion or basilar artery occlusion, using cerebral angiography in 12 patients, including 8 patients with basilar artery occlusion and 4 patients with double intracranial vertebral artery occlusion. Among the 8 patients with basilar artery 
Table 1. Patients' history

\begin{tabular}{|c|c|c|c|c|c|c|c|c|c|c|c|c|c|c|}
\hline $\begin{array}{l}\text { Case } \\
\text { No. }\end{array}$ & $\begin{array}{l}\text { Age, } \\
\text { years }\end{array}$ & Sex & $\begin{array}{l}\text { Risk } \\
\text { fac- } \\
\text { tors }\end{array}$ & $\begin{array}{l}\text { NIHSS } \\
\text { score }^{a}\end{array}$ & $\begin{array}{l}\text { Vascular } \\
\text { occlusion }\end{array}$ & TOAST & $\begin{array}{l}\text { Time, } \\
\mathrm{h}^{\mathrm{b}}\end{array}$ & $\begin{array}{l}\text { Compen- } \\
\text { sation }\end{array}$ & TIMI & $\begin{array}{l}\text { Haem- } \\
\text { orrhage }\end{array}$ & $\begin{array}{l}\text { mRS } \\
\text { score }^{c}\end{array}$ & $\begin{array}{l}\text { NIHSS } \\
\text { score }^{d}\end{array}$ & $\begin{array}{l}\text { Anti- } \\
\text { platelet } \\
\text { therapy }\end{array}$ & $\begin{array}{l}\mathrm{mRS} \\
\text { score }^{\mathrm{e}}\end{array}$ \\
\hline 1 & 64 & M & 2 & 30 & BA, LA & LAA & 27 & yes $^{f}$ & 3 & no & 3 & 14 & $\mathrm{cl}$ & 2 \\
\hline 2 & 46 & M & 2 & 11 & LA, BA & LAA & 170 & yes $^{f}$ & 2 & no & 2 & 7 & $\mathrm{cl}+\mathrm{as}$ & 1 \\
\hline 3 & 77 & M & 0 & 25 & $\mathrm{BA}$ & LAA & 48 & yes $^{f}$ & 2 & no & 5 & NA & $\mathrm{cl}$ & $d$ \\
\hline 4 & 63 & M & 2 & 7 & LA, RA & LAA & 336 & yes $^{f}$ & 3 & no & 0 & 3 & $\mathrm{cl}+\mathrm{as}$ & 0 \\
\hline 5 & 75 & M & 2 & 40 & BA, LA, RA & LAA & 10 & no & 3 & yes & 5 & NA & NA & $\mathrm{d}$ \\
\hline 6 & 71 & M & 4 & 8 & LA, BA, CA & LAA & 24 & yes $^{\mathrm{f}}$ & 3 & no & 2 & 2 & $\mathrm{cl}+\mathrm{as}$ & $2^{\mathrm{i}}$ \\
\hline 7 & 40 & M & 1 & 10 & LA, RA & LAA & 96 & yes $^{g}$ & 3 & no & 0 & 0 & $\mathrm{cl}+\mathrm{as}$ & 0 \\
\hline 8 & 51 & M & 2 & 17 & $\mathrm{BA}$ & LAA & 14 & yes $^{f}$ & 3 & no & 3 & 8 & $\mathrm{cl}+\mathrm{as}$ & 2 \\
\hline 9 & 71 & M & 3 & 18 & LA, BA & LAA & 12 & no & 3 & no & 4 & 25 & $\mathrm{cl}+\mathrm{as}$ & 4 \\
\hline 10 & 41 & M & 4 & 11 & LA, RA & LAA & 48 & yes $^{\mathrm{f}}$ & 3 & no & 2 & 2 & $\mathrm{cl}+\mathrm{as}$ & 0 \\
\hline 11 & 62 & M & 3 & 10 & LA, RA & LAA & 336 & yes $^{g}$ & 3 & no & 0 & 0 & $\mathrm{cl}+\mathrm{as}$ & 0 \\
\hline 12 & 64 & M & 2 & 12 & $\mathrm{RA}, \mathrm{BA}$ & LAA & 23 & yes $^{\text {h }}$ & 3 & no & 3 & 6 & $\mathrm{cl}$ & 3 \\
\hline
\end{tabular}

NIHSS, National Institute of Health Stroke Scale; BA, basilar artery; LA, left vertebral artery; RA, right vertebral artery; CA, coronary artery; LAA, large artery atherosclerosis; mRS, modified Rankin scale; NA, not applicable; cl, Plavix; as, Bayaspirin; d, death. ${ }^{a}$ Baseline NIHSS score. ${ }^{b}$ Time from onset to puncture. ${ }^{c}$ mRS score when leaving hospital. ${ }^{d}$ NIHSS score when leaving hospital. ${ }^{\mathrm{e}} \mathrm{mRS}$ score after 3 months. ${ }^{\mathrm{f}}$ Meningeal branch artery. ${ }^{\mathrm{g}}$ Anterior spinal artery. ${ }^{\mathrm{h}}$ Posterior communicating artery. ${ }^{\mathrm{i}}$ One year after operation.

Table 2. Characteristics of patients

\begin{tabular}{lc}
\hline Characteristics & $n(\%)$ \\
\hline Age & \\
$\quad \geq 60$ years & $8(66.7)$ \\
$\quad<60$ years & $4(33.3)$ \\
Risk factors & $11(91.7)$ \\
$\quad$ High blood pressure & $3(25.0)$ \\
Diabetes mellitus & $6(50.0)$ \\
Dyslipidaemia & $2(16.7)$ \\
History of stroke & $0(0)$ \\
Atrial fibrillation & $4(33.3)$ \\
Smoking & $8(66.7)$ \\
Occlusion site & $4(33.3)$ \\
$\quad$ Basilar artery & $12(100)$ \\
$\quad$ Bilateral vertebral artery &
\end{tabular}

occlusion, there were 4 patients who also had single vertebral artery stenosis or occlusion; compensation of the basilar artery from the anterior circulation was found in 1 patient, pial collateralization to the posterior circulation was found in 5 patients, and no collateral pathways were found in 2 patients. Angiographic findings revealed collateral pathways through the anterior spinal artery and the meningeal branch artery in 4 patients with double intracranial vertebral artery occlusion. Twelve patients had progressive deterioration of disease after onset. Baseline National Institute of Health Stroke Scale (NIHSS) scores on admission ranged from 7 to 40 (average 16.6).

Because all patients were beyond the time window to receive IVT and because it was unclear whether there were fresh blood clots in the occlusive artery, we advanced a micro-guidewire and a micro-catheter through the occluded lesion to the distal normal vascular lumen. Then, the micro-guidewire was withdrawn, 
Table 3. Operation and clinical prognosis

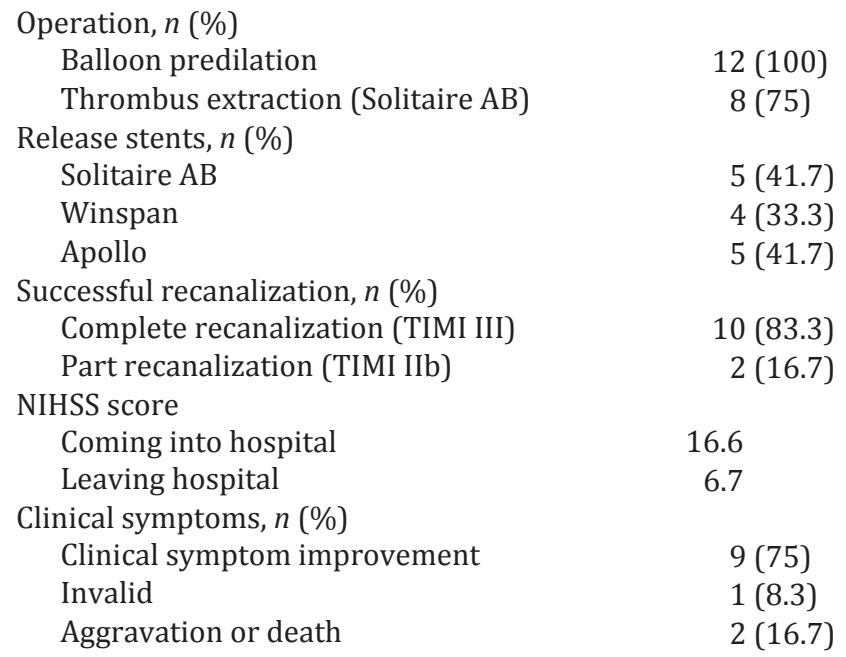

$12(100)$

16.6

6.7

NIHSS, National Institute of Health Stroke Scale.
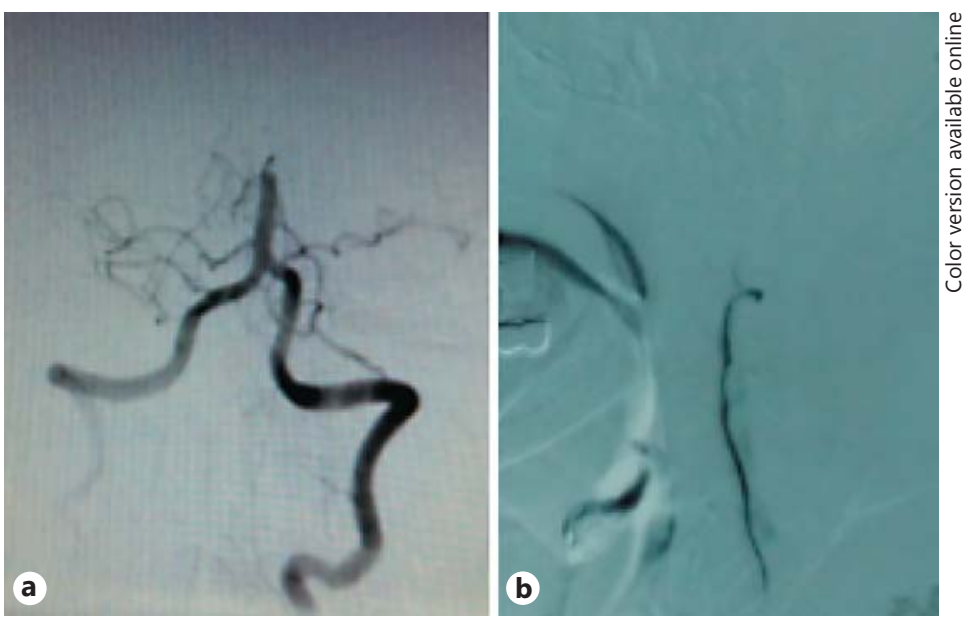

Fig. 1. One case of basilar artery occlusion recanalization. a Distal basilar artery occlusion before operation. b After being treated with thrombectomy.

and the vascular occlusion site was determined via micro-catheter angiography. After expanding the occluded area with a small Gateway balloon $(1.5 \mathrm{~mm})$, we analysed the cause of occlusion based on the vascular appearance on micro-catheter angiography, the vascular resistance during balloon dilatation, and blood flow velocity and blood flow volume with or without filling defect after balloon dilatation. If vascular stenosis was observed, we gave priority to dilatation with a larger-diameter balloon, but we performed an emergency stent implantation when vessel dissection occurred or when the artery could not be recanalized during the operation. In addition, we performed a thrombectomy with retrievable stent placement when thrombosis was considered. One patient received only balloon dilation due to the large area of the brain stem infarct. Thrombus extraction was applied using Solitaire AB stents in 8 patients. Only 1 patient received thrombectomy. During the operation, thrombectomy stents were released in 5 patients, balloon dilation followed by stent implantation was used due to occlusions caused by haematostenosis in 3 patients, an intracranial balloon-expandable stent (Apollo) and a self-expanding stent (Winspan) were simultaneously used in 1 patient due to long segmental arterial lesions, Apollo stents were used in 2 patients, and periphery stent (Hippocampus Invatec) and a coronary stent were applied consecutively in 2 patients complicated by extracranial vertebral artery stenosis. After the operation, the arteries of all patients were recanalized. The Thrombolysis in Myocardial Infarction (TIMI) score recovered to level 3 in 10 patients and to level 2 in 2 patients, 

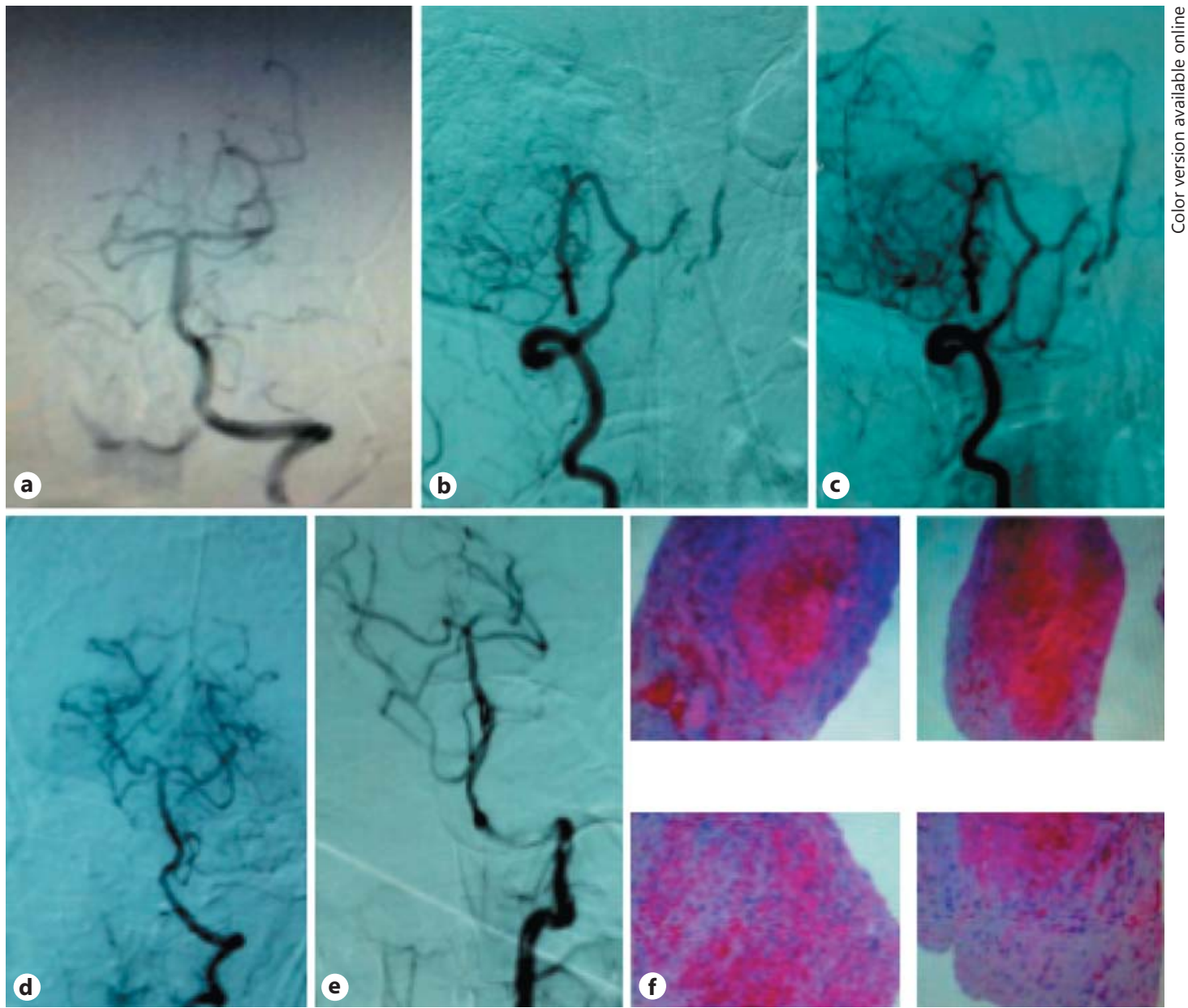

Fig. 2. Another case with double intracranial vertebral artery occlusion. a Intracranial left vertebral artery occlusion. b, c Intracranial right vertebral artery occlusion (after posterior inferior cerebellar artery); basilar artery, contralateral vertebral artery and contralateral posterior inferior cerebellar artery were compensated by anterior spinal artery. $\mathbf{d}$ Normal blood flow after thrombectomy stent implantation during the operation and thrombus could be seen. e Normal blood flow and desirable angioplasty after thrombus extraction by stents. $\mathbf{f}$ Submitted histopathologic slide indicates mixed thrombus.

and severe residual stenosis was found in 2 patients. Postoperative residual stenosis of approximately $60 \%$ was seen in one patient who received only balloon dilation due to the large area of the brain stem infarct, and residual stenosis of approximately 50\% was seen in another patient because balloon dilation had no effect on calcification of the parent artery. Residual stenosis of all the other patients was below 50\% (average 15\%) (Tables 1, 3).

After the operation, 1 patient died from a haemorrhage related to high perfusion, another patient died due to pulmonary infection 2 months later, and no complications were found in the other 10 patients. The NIHSS scores ranged from 0 to 25 (average 6.7) at discharge from the hospital. All patients took drugs regularly at home to prevent risk factors (PLAVIX $75 \mathrm{mg}$ per day plus aspirin $100 \mathrm{mg}$ per day plus Lipitor $20 \mathrm{mg}$ per day). After 3 months of follow-up of the 10 patients, in-stent restenosis was revealed in 1 patient, no aggravation of restenosis was found in the patient who received only balloon dilation treatment, and stroke did not recur in any patients. The NIHSS scores of the 10 patients ranged from 0 to 25 (average 3.9). Two of the patients had poor outcomes due to the large area of the brain stem infarction, and their modified Rankin scale (mRS) scores were 3 and 4 . The other 8 patients were able to live independently, and their mRS scores were 0 ( 4 patients), 1 (1 patient) and 2 (3 patients) (Figs. $1-3)$. 

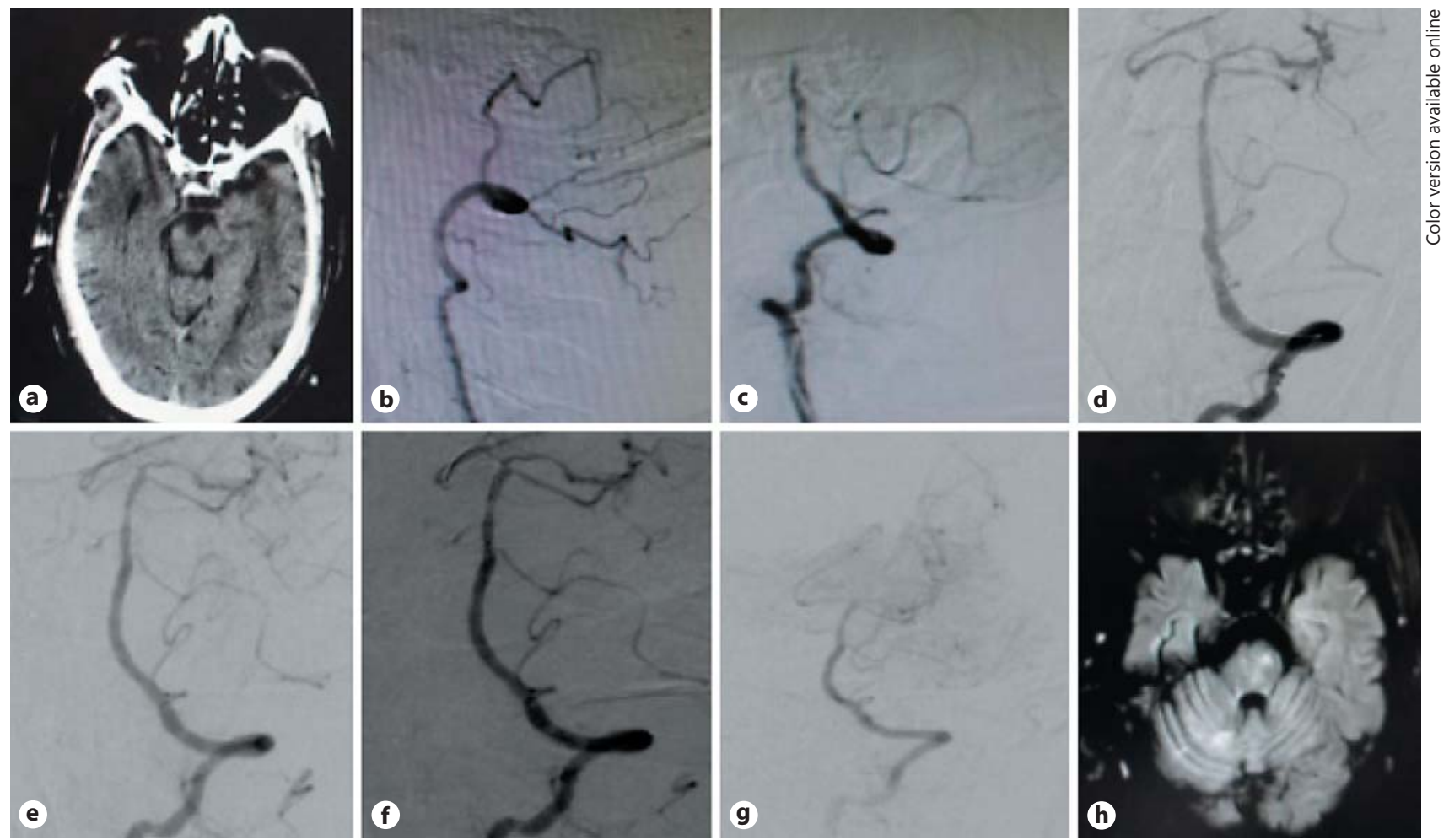

Fig. 3. Imaging of case 12. a Brain computed tomography before operation. b Right vertebral artery occlusion before operation. c Basilar artery occlusion before operation. $\mathbf{d}-\mathbf{g}$ Revascularization of basilar artery after operation. $\mathbf{h}$ Magnetic resonance imaging before hospital discharge.

\section{Discussion}

Kubik and Adams [6] first provided a detailed description of basilar artery occlusion in 1946. Approximately $60 \%$ of such patients experienced transient ischemic attack with aura: dizziness, nausea, headache and some more severe complications like quadriplegia and locked-in syndrome. Acute basilar artery occlusion has poor outcomes with a $90 \%$ mortality rate in the absence of treatment $[7,8]$. It was stated that IVT has a limited effect on basilar artery occlusion, and the likelihood of mortality following IAT was 55-70\% [5, 7-9]. Several studies showed that recanalization is the most important prognostic factor for good functional outcomes [10]. The multimodal reperfusion approach has been the first choice for acute basilar artery occlusion $[11,12]$, and urgent recanalization could improve prognosis $[5$, $9,10,13]$. In our study, all patients were clearly beyond the optimal time window to receive thrombolysis, and their symptoms worsened after urgent drug therapy. All the occluded arteries were recanalized.

The main causes of acute basilar artery occlusion are atherothrombotic occlusions due to local thrombosis on the basis of severe stenosis and embolic occlusion resulting from cardiac or arterio-arterial thromboembolism. Atherothrombotic lesions are found in approximately 26-36\% of patients with acute basilar artery occlusion. Embolic occlusions account for approximately $30-35 \%$ of acute basilar artery occlusion cases and occur more often in the distal segment of the basilar artery $[5,7,11,13-15]$. The Chinese population has an even higher prevalence of intracranial atherosclerosis than Caucasian populations [16]. The Chinese Intracranial Atherosclerosis (CICAS) trial evaluated 2,864 consecutive patients with 
cerebral ischaemia and found a prevalence of intracranial atherosclerosis of $46.6 \%$ [17]. Atherothrombotic occlusions are the more common cause of acute brain stroke instead of embolic occlusion. Remarkably, a longer duration since symptom onset increased operative difficulty and produced a higher operative risk [18]. No risk factors of cardiac embolism were found in all 12 patients. Arteriosclerosis, as revealed by angiography, was the cause of thrombosis in all patients. If stenosis led to vascular occlusion, direct thrombectomy with a retrievable stent was likely incomplete, made recovery difficult and also aggravated vascular endothelial damage. Therefore, we conducted a small-balloon expansion to block blood vessels and to determine whether the blocked areas induced vascular stenosis.

After expanding the occluded parts with a small Gateway balloon $(1.5 \mathrm{~mm})$, we analysed the cause of the occlusion according to the vascular appearance on micro-catheter angiography, the vascular resistance during balloon dilatation, and blood flow velocity and blood flow volume with or without a filling defect after balloon dilation. If vascular stenosis was found, we gave priority to dilation of a larger-diameter balloon, but we implanted an emergency stent when vessel dissection occurred or when the artery could not be recanalized during the operation. In addition, we performed a thrombectomy with retrievable stent placement when thrombosis was considered. Stent thrombectomy was performed in 8 patients, including 1 patient who received only thrombus extraction and 7 patients who received thrombectomy stent implantation after thrombus extraction. Several special stents were placed in 5 patients due to the extended length of the occlusion lesion, including a balloon-expandable stent (Apollo) in 1 patient and a self-expandable stent (Winspan) in 4 patients. One month after the operation, one patient died from brain stem infarction complicated by haemothorax and serious pulmonary infection, and another patient died from hypertransfusion haemorrhage. Only 1 patient did not undergo stent implantation due to severe calcification of the occlusion site in the parent artery, with a degree of residual stenosis of $50 \%$ after balloon predilation. Another patient was treated with only smallballoon dilatation to decrease the risk of high perfusion because of the large brain stem infarct area and the short time since symptom onset ( 2 days). The degree of postoperative residual stenosis was approximately $60 \%$. The postoperative blood TIMI of all patients recovered to level 2 or 3 ( 2 patients recovered to level 2 , and the rest of the patients recovered to level 3).

In 2015, several published randomized studies reported that the Solitaire retrievable stent was safe for cases of acute ischaemic stroke complicated with proximal large artery occlusion of the anterior circulation and without massive cerebral infarction and improved functional prognosis compared to drug therapy [19-22]. To date, there has been no study of posterior circulation occlusion. In the present study, we included 12 patients with non-superacute vertebral basilar artery occlusion; 2 of these patients died of postoperative pulmonary infection or hypertransfusion haemorrhage, and the average NIHSS score of the other 10 patients was $7.9 \pm 8.7$ at the time of hospital discharge. After 3 months of follow-up, the mRS scores of all patients were below 2 (average $1.3 \pm 1.4$ ), and the average NIHSS score in 8 patients was $3.9 \pm 7.9$. Postoperative restenosis was found in only 1 patient, and this patient had high-grade residual stenosis. There was no recurrence of ischaemic events during followup, and the longest follow-up duration was 2 years.

For patients with large artery occlusion in the posterior circulation, especially vertebral basilar artery occlusion, the medical condition may worsen even if urgent drug therapy is administered. Multimodal artery recanalization can be attempted even if the onset time exceeds the time window for thrombectomy. This study has inherent limitations due to the small number of patients from a single centre, and further prospective studies and controlled studies should be conducted to verify the effect and safety of multimodal artery recanalization in the acute stage. 


\begin{tabular}{l|l}
\hline Intervent Neurol 2017;6:254-262 \\
\hline DOI: 10.1159/000477626 & $\begin{array}{l}\text { @ 2017 S. Karger AG, Basel } \\
\text { www.karger.com/ine }\end{array}$ \\
\hline
\end{tabular}

He et al.: Multimodal Therapy for Non-Superacute Vertebral Basilar Artery Occlusion

\section{Acknowledgement}

The project is supported by the Science and Technology plan projects of Guangzhou (2014Y2-00501).

\section{Disclosure Statement}

The authors have no conflicts of interest.

\section{References}

1 Lindsberg PJ, Soinne L, Tatlisumak T, Roine RO, Kallela M, Happola O, Kaste M: Long-term outcome after intravenous thrombolysis of basilar artery occlusion. JAMA 2004;292:1862-1866.

2 Smith WS: Intra-arterial thrombolytic therapy for acute basilar occlusion: pro. Stroke 2007;38(suppl 2):701703.

3 Lee CY, Ryu CW, Koh JS, Kim GK: Late spontaneous recanalization of chronic middle cerebral artery occlusion. Neurointervention 2012; 7:113-116.

4 Vahedi K, Hofmeijer J, Juettler E, Vicaut E, George B, Algra A, Amelink GJ, Schmiedeck P, Schwab S, Rothwell PM, Bousser MG, van der Worp HB, Hacke W; DECIMAL, DESTINY, and HAMLET investigators: Early decompressive surgery in malignant infarction of the middle cerebral artery: a pooled analysis of three randomised controlled trials. Lancet Neurol 2007;6:215-222.

5 Schonewille WJ, Wijman CA, Michel P, Rueckert CM, Weimar C, Mattle HP, Engelter ST, Tanne D, Muir KW, Molina CA, Thijs V, Audebert H, Pfefferkorn T, Szabo K, Lindsberg PJ, de Freitas G, Kappelle LJ, Algra A; BASICS study group: Treatment and outcomes of acute basilar artery occlusion in the Basilar Artery International Cooperation Study (BASICS): a prospective registry study. Lancet Neurol 2009;8:724-730.

6 Kubik CS, Adams RD: Occlusion of the basilar artery; a clinical and pathological study. Brain 1946;69:73-121.

7 Brandt T: Diagnosis and thrombolytic therapy of acute basilar artery occlusion: a review. Clin Exp Hypertens 2002;24:611-622.

8 Hacke W, Zeumer H, Ferbert A, Bruckmann H, del Zoppo GJ: Intra-arterial thrombolytic therapy improves outcome in patients with acute vertebrobasilar occlusive disease. Stroke 1988;19:1216-1222.

9 Schulte-Altedorneburg G, Hamann GF, Mull M, Kuhne D, Liebetrau M, Weber W, Bruckmann H, Mayer TE: Outcome of acute vertebrobasilar occlusions treated with intra-arterial fibrinolysis in 180 patients. AJNR Am J Neuroradiol 2006;27:2042-2047.

10 Davis SM, Donnan GA: Basilar artery thrombosis: recanalization is the key. Stroke 2006;37:2440.

11 Mordasini P, Brekenfeld C, Byrne JV, Fischer U, Arnold M, Heldner MR, Ludi R, Mattle HP, Schroth G, Gralla J: Technical feasibility and application of mechanical thrombectomy with the Solitaire FR Revascularization Device in acute basilar artery occlusion. AJNR Am J Neuroradiol 2013;34:159-163.

12 Raphaeli G, Eichel R, Ben-Hur T, Leker RR, Cohen JE: Multimodal reperfusion therapy in patients with acute basilar artery occlusion. Neurosurgery 2009;65:548-552; discussion 552-553.

13 Eckert B, Kucinski T, Pfeiffer G, Groden C, Zeumer H: Endovascular therapy of acute vertebrobasilar occlusion: early treatment onset as the most important factor. Cerebrovasc Dis 2002;14:42-50.

14 Brandt T, von Kummer R, Muller-Kuppers M, Hacke W: Thrombolytic therapy of acute basilar artery occlusion. Variables affecting recanalization and outcome. Stroke 1996;27:875-881.

15 Castaigne P, Lhermitte F, Gautier JC, Escourolle R, Derouesne C, Der Agopian P, Popa C: Arterial occlusions in the vertebro-basilar system. A study of 44 patients with post-mortem data. Brain 1973;96:133-154.

16 Wong KS, Li H: Long-term mortality and recurrent stroke risk among Chinese stroke patients with predominant intracranial atherosclerosis. Stroke 2003;34:2361-2366.

17 Wang Y, Zhao X, Liu L, Soo YO, Pu Y, Pan Y, Wang Y, Zou X, Leung TW, Cai Y, Bai Q, Wu Y, Wang C, Pan X, Luo B, Wong KS, Group CS: Prevalence and outcomes of symptomatic intracranial large artery stenoses and occlusions in China: the Chinese Intracranial Atherosclerosis (CICAS) Study. Stroke 2014;45:663-669.

18 Mori T, Fukuoka M, Kazita K, Mori K: Follow-up study after intracranial percutaneous transluminal cerebral balloon angioplasty. AJNR Am J Neuroradiol 1998;19:1525-1533.

19 Saver JL, Goyal M, Bonafe A, Diener HC, Levy EI, Pereira VM, Albers GW, Cognard C, Cohen DJ, Hacke W, Jansen O, Jovin TG, Mattle HP, Nogueira RG, Siddiqui AH, Yavagal DR, Baxter BW, Devlin TG, Lopes DK, Reddy VK, du Mesnil de Rochemont R, Singer OC, Jahan R; SWIFT PRIME Investigators: Stent-retriever thrombectomy after intravenous t-PA versus t-PA alone in stroke. N Engl J Med 2015;372:2285-2295. 
20 Goyal M, Demchuk AM, Menon BK, Eesa M, Rempel JL, Thornton J, Roy D, Jovin TG, Willinsky RA, Sapkota BL, Dowlatshahi D, Frei DF, Kamal NR, Montanera WJ, Poppe AY, Ryckborst KJ, Silver FL, Shuaib A, Tampieri D, Williams D, Bang OY, Baxter BW, Burns PA, Choe H, Heo JH, Holmstedt CA, Jankowitz B, Kelly M, Linares G, Mandzia JL, Shankar J, Sohn SI, Swartz RH, Barber PA, Coutts SB, Smith EE, Morrish WF, Weill A, Subramaniam S, Mitha AP, Wong JH, Lowerison MW, Sajobi TT, Hill MD; ESCAPE Trial Investigators: Randomized assessment of rapid endovascular treatment of ischemic stroke. N Engl J Med 2015;372:1019-1030.

21 Campbell BC, Mitchell PJ, Kleinig TJ, Dewey HM, Churilov L, Yassi N, Yan B, Dowling RJ, Parsons MW, Oxley TJ, Wu TY, Brooks M, Simpson MA, Miteff F, Levi CR, Krause M, Harrington TJ, Faulder KC, Steinfort BS, Priglinger M, Ang T, Scroop R, Barber PA, McGuinness B, Wijeratne T, Phan TG, Chong W, Chandra RV, Bladin CF, Badve M, Rice H, de Villiers L, Ma H, Desmond PM, Donnan GA, Davis SM; EXTEND-IA Investigators: Endovascular therapy for ischemic stroke with perfusion-imaging selection. N Engl J Med 2015;372:1009-1018.

22 Berkhemer OA, Fransen PS, Beumer D, van den Berg LA, Lingsma HF, Yoo AJ, Schonewille WJ, Vos JA, Nederkoorn PJ, Wermer MJ, van Walderveen MA, Staals J, Hofmeijer J, van Oostayen JA, Lycklama a Nijeholt GJ, Boiten J, Brouwer PA, Emmer BJ, de Bruijn SF, van Dijk LC, Kappelle LJ, Lo RH, van Dijk EJ, de Vries J, de Kort PL, van Rooij WJ, van den Berg JS, van Hasselt BA, Aerden LA, Dallinga R J, Visser MC, Bot JC, Vroomen PC, Eshghi O, Schreuder TH, Heijboer RJ, Keizer K, Tielbeek AV, den Hertog HM, Gerrits DG, van den Berg-Vos RM, Karas GB, Steyerberg EW, Flach HZ, Marquering HA, Sprengers ME, Jenniskens SF, Beenen LF, van den Berg R, Koudstaal PJ, van Zwam WH, Roos YB, van der Lugt A, van Oostenbrugge RJ, Majoie CB, Dippel DW; MR CLEAN Investigators: A randomized trial of intraarterial treatment for acute ischemic stroke. N Engl J Med 2015;372: $11-20$. 